\title{
Endotoxin clustering with allergens in house dust and asthma outcomes in a U.S. national study
}

\author{
Angelico Mendy ${ }^{1}$, Jesse Wilkerson², Päivi M. Salo ${ }^{3}$, Darryl C. Zeldin ${ }^{3}$ and Peter S. Thorne ${ }^{1,4^{*}}$
}

\begin{abstract}
Background: Endotoxin is ubiquitous in the environment, but its clustering with indoor allergens is not well characterized. This study examined the clustering patterns of endotoxin with allergens in house dust and their association with asthma outcomes.

Methods: We analyzed data from 6963 participants of the 2005-2006 National Health and Nutrition Examination Survey. House dust sampled from bedroom floor and bedding was evaluated for endotoxin and allergens from fungi, cockroach, dog, cat, mites, and rodents. Two-step cluster analysis and logistic regressions were performed to identify the clustering patterns and their associations with current asthma and wheeze in the past 12 months, adjusting for covariates.

Results: Of the homes, 17.8\% had low endotoxin and allergen levels in house dust (Cluster 1). High endotoxin level clustered with Alternaria and pet allergens in the homes of participants with a high socioeconomic status who own pets (Cluster 2) (48.9\%). High endotoxin clustered with Aspergillus, dust mites, cockroach, and rodent allergens in the homes of participants with low socioeconomic status (Cluster 3) (33.3\%). Compared to Cluster 1, Cluster 2 was associated with higher asthma prevalence (OR 1.42, 95\% Cl: 1.06-1.91) and wheeze (OR 1.32, 95\% Cl: 1.07-1.63). Cluster 3 was positively associated with wheeze only in participants sensitized to inhalant allergens (OR 1.42, 95\% Cl: 1.06-1.91) or exposed to tobacco smoke (OR 1.72, 95\% Cl: 1.15-2.60).
\end{abstract}

Conclusions: The clustering of endotoxin with allergens in dust from homes with pets or of people with low socioeconomic status is associated with asthma and wheeze.

Keywords: Allergens, Asthma, Cluster analysis, Endotoxin, House dust, Wheeze

\section{Introduction}

Asthma is a chronic respiratory disorder characterized by bronchoconstriction, pulmonary inflammation, as well as airway remodeling with symptoms of wheezing, cough, and shortness of breath [1]. It affects over 350 million people around the world and was responsible for approximately 400,000 deaths in 2015 [2]. In the U.S., 24.6 million

\footnotetext{
* Correspondence: peter-thorne@uiowa.edu

'Department of Occupational and Environmental Health, University of lowa, lowa City, lowa, USA

${ }^{4}$ University of lowa College of Public Health, 100 CPHB, S341A, $145 \mathrm{~N}$ Riverside Dr, lowa City, IA 52242-2207, USA

Full list of author information is available at the end of the article
}

people currently have the condition, about 4000 people die from it every year and its annual economic cost is estimated to be over $\$ 56$ billion [3, 4]. Asthma has a familial and genetic component, but home exposures are major risk factors for the development of the disease $[5,6]$. We previously reported that endotoxin, a lipopolysaccharide in the cell wall of Gram-negative bacteria, was associated with a higher prevalence of asthma outcomes and chronic bronchitis or emphysema in the U.S. [7-9]. On the other hand, some reports suggest that exposure to low levels of endotoxin during early childhood could protect against allergy-mediated asthma [10]. Endotoxin is ubiquitous in

(c) The Author(s). 2020 Open Access This article is licensed under a Creative Commons Attribution 4.0 International License, which permits use, sharing, adaptation, distribution and reproduction in any medium or format, as long as you give appropriate credit to the original author(s) and the source, provide a link to the Creative Commons licence, and indicate if changes were made. The images or other third party material in this article are included in the article's Creative Commons licence, unless indicated otherwise in a credit line to the material. If material is not included in the article's Creative Commons licence and your intended use is not permitted by statutory regulation or exceeds the permitted use, you will need to obtain permission directly from the copyright holder. To view a copy of this licence, visit http://creativecommons.org/licenses/by/4.0/ The Creative Commons Public Domain Dedication waiver (http://creativecommons.org/publicdomain/zero/1.0/) applies to the data made available in this article, unless otherwise stated in a credit line to the data. 
our environment, but it is found at higher concentration in farms and in the homes of individuals with low socioeconomic status, or in households with the presence of children, carpeting, pets, cockroaches, or with a smoker $[8,11-13]$.

Previous studies have indicated that most U.S. homes have simultaneous exposures to endotoxin and multiple allergens; however, the clustering of endotoxin and allergens in house dust is not well characterized $[8,12,14,15]$. Prior reports have investigated the association of individual exposures to endotoxin or allergens with asthma and other respiratory outcomes [7-9, 16-18]. Co-exposure to multiple allergens and toxicants can also have health effects that cannot be predicted by separately evaluating the individual exposures [19]. House dust endotoxin and allergens do not exist in isolation but cluster with each other following different patterns and the association of these clusters with asthma outcomes is unknown [15]. Therefore, the aim of this study was to examine the clustering patterns of endotoxin and allergens in house dust and their association with asthma outcomes in the National Health and Nutrition Examination Survey (NHANES). The NHANES is the largest study on endotoxin and asthma to date and provides a unique opportunity to study the question [8]. It includes close to 7000 samples and measures the concentration of several allergens in homes (fungi, cockroach, dog, cat, dust mites, and rodents).

\section{Materials and methods}

\section{Data source and study design}

We used data from the 2005-2006 cycle of the NHANES. The NHANES is a continuous cross-sectional survey of the U.S. non-institutionalized civilian population conducted by the National Center for Health Statistics (NCHS) of the Centers for Disease Control and Prevention (CDC). It uses a complex multistage sampling design to derive a sample representative of the U.S. population. Of the 9440 total NHANES participants, 6963 dust samples were analyzed for endotoxin and allergen content. NHANES procedures and methods are further described at http://www.cdc.gov/nchs/nhanes/survey_methods.htm.

\section{Endotoxin and allergens analysis}

Dust was collected from the bed and bedroom floor of each participant's home with a Sanitaire ${ }^{\mathrm{Tm}}$ Model 3683 vacuum cleaner and a Mitest ${ }^{\text {tim }}$ Dust Collector (Indoor Biotechnologies, Inc., Charlottesville, VA). A 1-square yard (0.84 $\mathrm{m}^{2}$ ) surface on both bed and adjacent floor was independently vacuumed for $2 \mathrm{~min}$. Details on the dust collection methods are available at https:/www.cdc.gov/nchs/data/ nhanes/nhanes_05_06/allergen_manual_06.pdf). The combined dust samples were analyzed for endotoxin content at the University of Iowa Pulmonary Toxicology Facility using a kinetic chromogenic Limulus amebocyte lysate assay with extensive quality assurance measures. Endotoxin concentrations were reported in Endotoxin Units (EU) per mass of sieved dust (mg) with a lower limit of detection of $0.0005 \mathrm{EU} / \mathrm{mg}$.

The sample were also analyzed for the following allergens: fungi (Alternaria alternata [Alt a 1]), dog (Canis familiaris [Can $\mathrm{f} 1]$ ), cat (Feline domesticus [Fel d 1]), dust mites (Dermatophagoides pteronyssinus [Der p 1] and Dermatophagoides farinae [Der f 1]), mouse (Mus musculus [Mus $\mathrm{m}$ 1]), and rat (Rattus norvegicus [Rat $\mathrm{n} \mathrm{1])} \mathrm{using} \mathrm{a}$ Multiplex Array for Indoor Allergens assay (MARIA; Indoor Biotechnologies, Charlottesville, VA). Cockroach allergen (Blatella germanica [Bla g 1]) was assayed by enzyme-linked immunosorbent assay (ELISA) test kits from Indoor Biotechnologies, Inc. (Charlottesville, VA) and Aspergillus fumigatus antigen was measured by ELISA using reagents from Greer Laboratories (Lenoir, NC).

\section{Asthma and wheeze definitions}

Current asthma was defined using the questions: "Has a doctor or other health professional ever told you that you had asthma?" and "Do you still have asthma?" Wheeze in past 12 months was defined using the question: "In the past 12 months have you had wheezing or whistling in your chest?"

\section{Covariates}

Data on age, gender, race/ethnicity, and family income were collected using questionnaires. Poverty income ratio (PIR) was estimated using guidelines and adjustment for family size, year and state. Participants were also asked about housing characteristics such as the presence of a smoker in the household, mildew or musty smell, cockroaches, pets (dog and cat), carpeted floor in the home, when the house was built, and the type of home.

Serum immunoglobulin E (IgE) specific to 15 inhalant allergens was measured (Alternaria alternata, Aspergillus fumigatus, Bermuda grass, birch, cat dander, cockroach, dog dander, dust mites [Der p 1 and Der f 1), mouse urine proteins, oak, ragweed, rat urine proteins, Russian thistle, and rye grass. Sensitization status was defined as specific IgE against any inhalant allergen $\geq 0.35 \mathrm{kU} / \mathrm{L}$.

\section{Statistical analysis}

We first explored the correlation between house dust endotoxin and allergens by means of the Pearson method to calculate correlation coefficients $(r)$. The cluster analysis was done in a two-step approach. In the first step, hierarchical cluster analysis was done using the Ward's method to generate a dendrogram from which the number of likely clusters within our population was estimated. This estimate was then pre-specified in a kmeans cluster analysis used as the principal clustering technique. The allergen concentrations in dust were log- 
transformed to approximate a normal distribution and standardized using z-scores. Descriptive analysis was performed and $P$-values for differences in proportions between the clusters were calculated using a chi-square test. Multivariable logistic regression was used to assess the association of each cluster with the prevalence of asthma and wheeze and odds ratios (OR) with corresponding confidence intervals $(\mathrm{CI})$ were reported. The models were adjusted for age, gender, race/ethnicity, PIR, and exposure to environmental tobacco smoke (ETS). Subgroup analysis by age groups, sensitization status to inhalant allergens, and exposure to environmental tobacco smoke were performed. Effect modification was assessed by calculating the $p$-values for the interactions. All analyses were done in SAS (Version 9.4, SAS Institute, Cary, NC USA), accounting for NHANES sample weights and the complex study design in order to obtain unbiased national estimates. $P$-values $<0.05$ were considered statistically significant.

\section{Results}

Our study included 6963 dust samples collected from homes of participants who were mostly adults, nonHispanic White, and who had a PIR $\geq 1.85$. They also tended to live in detached family houses, in homes built before 1978, in homes without a smoker, mildew/musty smell, cockroaches, or pet (dog or cat), but with carpeted floor (Table 1). The correlation between house dust endotoxin and allergens levels as well as the dendrogram showing the correlation coefficient distance between the exposures are shown in Fig. 1. The strongest relationships were observed between Alternaria alternata and rat allergens $(r=0.49)$, between dust mites (Der p 1 and Der f 1 ) $(r=0.41)$, and between Alternaria alternata and cat allergens $(r=0.35)$. Endotoxin was correlated with all the studied allergens with correlation coefficients ranging between 0.09 and 0.26 .

In cluster analysis using the Ward's method, we identified three patterns of endotoxin clustering with allergens in house dust. The levels of endotoxin and allergens in the clusters are reported in Table 2 and the characteristics of the participants by cluster and in the total study population are described in Table 1. Cluster 1 included $17.8 \%$ of the participants and defines the subgroup with low concentrations of endotoxin and allergens in house dust. This cluster included participants with a high PIR who also had the lowest prevalence of dog and cat ownership. Cluster 2 included $48.9 \%$ of the participants and labels the clustering of high endotoxin with Alternaria, and pet allergens. This cluster had the particularity to include participants who had a high socioeconomic status (based on PIR and living in a detached family house) and the highest prevalence of dog and cat ownership. It also had the highest prevalence of current asthma and wheeze. Cluster 3 included $33.3 \%$ of the participants and describes the clustering of high endotoxin with Aspergillus, dust mites, cockroach, and rodent allergens. This cluster is characterized by participants with a low socio-economic status (based on the high prevalence of PIR $<1.85$ and of living in a trailer), who lived in homes built before 1978 with mildew or musty smell and cockroaches (Table 1).

Table 3 shows that the prevalence of sensitization to any inhalant allergen was not significantly different across clusters. However, in subgroup analysis by sensitization to specific allergens, Cluster 2 had the lowest prevalence of sensitization to dust mites and cockroach allergens among the clusters. Cluster 3 had a lower prevalence of sensitization to plant or grass allergens but had a higher prevalence of sensitization to rat allergens compared to the other clusters.

In adjusted logistic regression analysis, compared to Cluster 1 which had the lowest concentration of house dust endotoxin and allergens, Cluster 2 was associated with $42 \%$ higher prevalence of current asthma (OR 1.42, 95\% CI $1.06,1.91$ ) and $32 \%$ higher prevalence of wheeze in the past 12 months (OR 1.32, 95\% CI: 1.07, 1.63) in all participants. The association of Cluster 2 with wheeze in the past 12 months differed by age of participants $\left(P_{\text {interaction }}=0.002\right)$ and was only observed in adults (OR: $1.43,95 \%$ CI: 1.15 , 1.78), but not in children (OR: 0.98, 95\% CI: 0.70, 1.36). The association of Cluster 3 with wheeze in the past 12 months differed by sensitization status to inhalant allergens $\left(P_{\text {interaction }}=0.02\right)$ and by exposure to ETS $\left(P_{\text {interaction }}=\right.$ $0.003)$. The relationship was seen in participants sensitized to inhalant allergens (OR: 1.42, 95\% CI: 1.06, 1.91) but not in non-sensitized individuals (OR: $0.81,95 \% \mathrm{CI}: 0.61,1.07$ ) and in participants exposed to ETS (OR: 1.72, 95\% CI: 1.14, 2.60) but not in those non-exposed (OR: 0.84, 95\% CI: $0.64,1.09$ ) (Table 4).

When we examined effect modification by sensitization to specific inhalant allergens, the association of Cluster 2 with wheeze in the past 12 months was different with sensitization status to Der $\mathrm{f} 1\left(\mathrm{P}_{\text {interaction }}=0.03\right)$ and Der $\mathrm{p}$ $1\left(\mathrm{P}_{\text {interaction }}=0.02\right) \quad($ Supplemental Table $\mathrm{S} 1)$. In participants sensitized to these allergens, Cluster 2 was associated with a 2 -fold increase in the odds of wheeze in the 12 months (OR: 2.09, 95\% CI: 1.47, 2.97 in individuals sensitized to Der f 1 and OR: 2.51, 95\% CI: $1.51,3.33$ in individuals sensitized to Der p 1) (Supplemental Table S2). The association of Cluster 3 with wheeze in the past 12 months was also different with sensitization status to Der $\mathrm{f} 1\left(\mathrm{P}_{\text {interaction }}=0.02\right)$ or Der p $1\left(\mathrm{P}_{\text {interaction }}<0.001\right)$ (Supplemental Table S1). Cluster 3 was associated with higher prevalence of wheeze in the past 12 months among participants sensitized to Der f 1 (OR: 1.82, 95\% CI: $1.07,3.12$ ) or Der p 1 (OR: 2.21, 95\% CI: 1.30, 3.76). An inverse relationship between Cluster 3 and wheeze in the past 12 months was noted in participants who 
Table 1 Description of study participants by cluster, NHANES 2005-2006

\begin{tabular}{|c|c|c|c|c|c|}
\hline Participants and home characteristics & Cluster 1 & Cluster 2 & Cluster 3 & $P$-value & All participants \\
\hline Prevalence, \% & 17.8 & 48.9 & 33.3 & & 100 \\
\hline Age groups, \% & & & & $<0.001$ & \\
\hline$<6$ year & 5.9 & 6.1 & 8.9 & & 7.0 \\
\hline $6-17$ year & 9.6 & 19.9 & 17.5 & & 17.3 \\
\hline$\geq 18$ year & 84.6 & 73.9 & 73.5 & & 75.7 \\
\hline Gender, \% & & & & 0.25 & \\
\hline Male & 48.7 & 48.0 & 50.3 & & 48.9 \\
\hline Female & 51.3 & 52.0 & 49.7 & & 51.1 \\
\hline Race/ethnicity, \% & & & & $<0.001$ & \\
\hline Non-Hispanic Whites & 58.1 & 80.4 & 55.3 & & 68.1 \\
\hline Non-Hispanic Blacks & 23.8 & 4.1 & 18.3 & & 12.3 \\
\hline Mexican-Americans & 9.5 & 6.3 & 14.0 & & 9.4 \\
\hline Other & 8.6 & 9.2 & 12.4 & & 10.1 \\
\hline$P I R, \%$ & & & & $<0.001$ & \\
\hline$<1.85$ & 32.5 & 23.9 & 46.3 & & 32.8 \\
\hline$\geq 1.85$ & 67.5 & 76.1 & 53.7 & & 67.2 \\
\hline Smoker in home, \% & 17.8 & 21.2 & 19.4 & 0.45 & 20.0 \\
\hline Mildew or musty smell, \% & 14.5 & 14.3 & 21.0 & 0.006 & 16.6 \\
\hline Cockroaches in home, \% & 12.4 & 9.5 & 23.8 & $<0.001$ & 14.8 \\
\hline Dog in home, \% & 15.5 & 76.7 & 29.8 & $<0.001$ & 48.0 \\
\hline Cat in home, \% & 9.9 & 69.1 & 14.1 & $<0.001$ & 36.9 \\
\hline Floor covering, $\%$ & & & & 0.38 & \\
\hline Carpeted floor & 84.5 & 87.4 & 88.8 & & 87.3 \\
\hline Smooth surface & 11.6 & 9.0 & 7.9 & & 9.1 \\
\hline Combination carpet and smooth surface & 3.9 & 3.6 & 3.3 & & 3.6 \\
\hline When was home built, \% & & & & $<0.001$ & \\
\hline Before 1978 & 41.0 & 44.2 & 57.8 & & 47.8 \\
\hline After 1978 & 59.0 & 55.8 & 42.2 & & 52.2 \\
\hline Type of home, \% & & & & $<0.001$ & \\
\hline Trailer & 4.8 & 6.3 & 10.4 & & 7.4 \\
\hline Detached family house & 59.8 & 73.0 & 63.0 & & 67.3 \\
\hline Attached family house & 11.0 & 8.3 & 9.0 & & 9.0 \\
\hline Apartment & 24.4 & 12.3 & 17.6 & & 16.2 \\
\hline \multicolumn{6}{|l|}{ Respiratory outcomes, \% } \\
\hline Current asthma & 7.2 & 10.0 & 7.8 & 0.01 & 8.8 \\
\hline Wheezing in past 12 months & 13.6 & 18.3 & 14.3 & $<0.001$ & 16.2 \\
\hline
\end{tabular}

Abbreviations: PIR poverty income ratio. P-value for difference in prevalence between clusters calculated using chi-square test

were not sensitized to Der p 1 (OR: 0.80, 95\% CI: 0.65, 0.98) (Supplemental Table S2).

We tested sex of participants for effect modification to determine whether the association of the clusters with asthma outcomes differed by sex. In all participants, sex was not a significant effect modifier of the association of Cluster 2 with current asthma $\left(P_{\text {interaction }}=0.44\right)$, wheeze
$\left(P_{\text {interaction }}=0.72\right)$, and sensitization to inhalant allergens $\left(P_{\text {interaction }}=0.60\right)$. The same was observed for the association of Cluster 3 with current asthma $\left(\mathrm{P}_{\text {interaction }}=\right.$ $0.46)$, wheeze $\left(P_{\text {interaction }}=0.70\right)$, and sensitization to inhalant allergens $\left(P_{\text {interaction }}=0.63\right)$. In addition, sex was not a significant effect modifier when we stratified our analysis by the age of participants. 


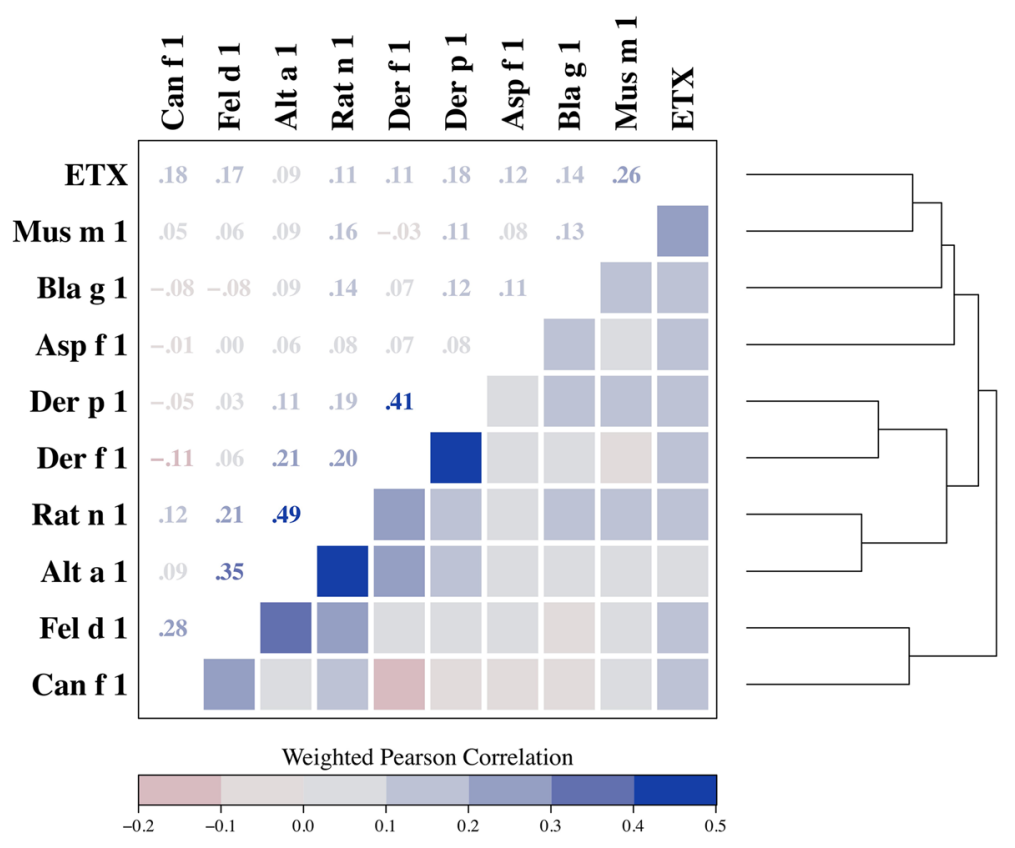

Fig. 1 Matrix for correlation between house dust endotoxin and allergens. The dendrogram illustrates the correlation coefficient distance between endotoxin and allergens. Abbreviations: ETX, Endotoxin; Mus m 1, mouse allergen; Bla g 1, cockroach allergen; Asp f 1, Aspergillus fumigatus; Der $\mathrm{p} 1$ and Der f 1, dust mites; Rat n 1, rat allergen; Alt 1, Alternaria alternata; Fel d 1, cat allergens; Can f 1, dog allergens.

Table 2 Levels of endotoxin and allergens in house dust overall and by cluster

\begin{tabular}{|l|r|r|r|r|}
\hline \multicolumn{1}{|l}{} & \multicolumn{1}{|c|}{ Overall } & \multicolumn{1}{c|}{ Cluster 1} & \multicolumn{1}{c|}{ Cluster 2} & \multicolumn{1}{c|}{ Cluster 3} \\
\hline Endotoxin (EU/mg), GM (SD) & $15.49(0.50)$ & $4.27(0.35)$ & $18.40(0.71)$ & $23.96(0.82)$ \\
\hline Aspergillus fumigatus (ng/g), GM (SD) & $109.50(1.37)$ & $85.92(2.59)$ & $105.67(2.51)$ & $131.60(4.20)$ \\
\hline Dog allergen (Can f 1) (ng/g), GM (SD) & $592.13(93.11)$ & $44.74(4.42)$ & $3,585.03(430.88)$ & $167.33(20.97)$ \\
\hline Dust mites (Der f 1) (ng/g), GM (SD) & $64.22(13.56)$ & $19.32(1.20)$ & $33.56(6.41)$ & $316.83(69.09)$ \\
\hline Dust mites (Der p 1) (ng/g), GM (SD) & $49.99(9.84)$ & $14.25(0.57)$ & $24.73(4.07)$ & $275.02(66.66)$ \\
\hline Cat allergen (Fel d 1) (ng/g), GM (SD) & $523.15(65.71)$ & $39.67(3.69)$ & $3,231.54(568.47)$ & $143.28(21.41)$ \\
\hline Mouse allergen (Mus m 1) (ng/g), GM (SD) & $16.67(2.43)$ & $5.00(0.31)$ & $16.36(3.47)$ & $32.62(5.54)$ \\
\hline Alternaria alternata (Alt a 1) (ng/g), GM (SD) & $4.03(0.13)$ & $3.30(0.06)$ & $4.34(0.19)$ & $4.02(0.15)$ \\
\hline Cockroach allergen (Bla g 1) (ng/g), GM (SD) & $0.44(0.01)$ & $0.37(0.02)$ & $0.39(0.01)$ & $0.57(0.03)$ \\
\hline Rat allergen (Rat n 1) (ng/g), GM (SD) & $4.55(0.20)$ & $3.30(0.05)$ & $4.75(0.27)$ & $5.06(0.27)$ \\
\hline
\end{tabular}

Abbreviations: GM Geometric mean; SD Standard Deviation

Cluster 1: Low concentration of endotoxin and low dust allergens. Cluster 2: High endotoxin clustering with pet allergens (Cat and Dog) and Alternaria. Cluster 3: High endotoxin clustering with Aspergillus, Dust Mites, Mouse and Rat, and Cockroach Allergens,

Blue shading indicates endotoxin or allergen concentration significantly lower than the population average. Orange shading indicates endotoxin or allergen concentration significantly higher than the population average. $P$-value for significance $<0.05$ 
Table 3 Prevalence of sensitization to specific inhalant allergens by cluster, NHANES 2005-2006

\begin{tabular}{|c|c|c|c|c|c|}
\hline Sensitization to inhalant allergens & Cluster 1 & Cluster 2 & Cluster 3 & P-value & All participants \\
\hline Any inhalant allergen & 43.8 & 44.2 & 43.1 & 0.79 & 43.8 \\
\hline Any dust mite & 22.1 & 15.8 & 24.1 & $<0.001$ & 19.6 \\
\hline Der f1 & 21.2 & 13.9 & 21.5 & $<0.001$ & 17.7 \\
\hline Der p1 & 20.7 & 14.5 & 21.7 & $<0.001$ & 18.0 \\
\hline Any pet allergen & 14.9 & 16.6 & 14.9 & 0.50 & 15.7 \\
\hline Dog & 12.0 & 12.0 & 11.2 & 0.84 & 11.7 \\
\hline Cat & 11.3 & 13.1 & 11.0 & 0.42 & 12.1 \\
\hline Any plant or grass allergen & 30.7 & 29.5 & 21.7 & $<0.001$ & 27.2 \\
\hline Ragweed & 18.2 & 16.1 & 13.3 & 0.06 & 15.6 \\
\hline Rye grass & 22.8 & 20.4 & 16.8 & 0.0078 & 19.7 \\
\hline Bermuda grass & 16.8 & 16.6 & 12.5 & 0.0044 & 15.3 \\
\hline Oak & 13.1 & 11.3 & 10.0 & 0.051 & 11.2 \\
\hline Birch & 10.8 & 10.2 & 9.0 & 0.43 & 9.9 \\
\hline Thistle & 12.8 & 11.8 & 9.3 & 0.053 & 11.2 \\
\hline Any mold allergen & 10.3 & 11.0 & 10.9 & 0.85 & 10.9 \\
\hline Alternaria alternata & 8.6 & 9.1 & 7.5 & 0.19 & 8.5 \\
\hline Aspergillus fumigatus & 6.3 & 6.3 & 7.0 & 0.66 & 6.5 \\
\hline Any rodent allergen & 1.8 & 1.7 & 2.3 & 0.36 & 2.0 \\
\hline Mouse & 1.4 & 0.9 & 1.2 & 0.63 & 1.1 \\
\hline Rat & 1.0 & 1.3 & 2.1 & 0.0018 & 1.5 \\
\hline Cockroach allergen & 11.8 & 7.7 & 12.2 & 0.0027 & 9.9 \\
\hline
\end{tabular}

Abbreviations: Der f Dermatophagoides farinae; Der $p$ Dermatophagoides pteronyssinus. P-value for difference in prevalence between clusters calculated using chi-square test

\section{Discussion}

In a sample representative of the U.S. population, we performed a cluster analysis to examine the patterns of endotoxin grouping with allergens in house dust. Our results show that homes with low endotoxin often had low levels of allergens in house dust (Cluster 1). High endotoxin tended to be associated with other allergens, following different patterns. In participants with high socio-economic status who own pets, endotoxin clustered with Alternaria and pet allergens in house dust and this cluster (Cluster 2) was positively associated with current asthma and wheeze in the past 12 months. In participants with low socioeconomic status and living in poor housing conditions, endotoxin clustered with Aspergillus, dust mites, cockroach, and rodent allergens and this cluster (Cluster 3) was only associated with wheeze in the past 12 months in those sensitized to dust mites or exposed to ETS.

Our study is the first to examine the clustering patterns of endotoxin with allergens. Previous reports explored the inter-relationship between endotoxin levels and the concentration of allergens [14]. A national U.S. study found that endotoxin levels increased with allergen burden and that endotoxin was specifically correlated with Alternaria, as well as with cockroach and mouse allergens [15]. These results are comparable to our findings in Cluster 3 where we reported a clustering of endotoxin with Aspergillus, cockroach and mouse allergens [15]. In Europe, a study found endotoxin to be positively correlated with $(1 \rightarrow 3)-\beta$ D-glucans, but not with dust mites, dog, cat, and cockroach allergens [20]. In Germany, Gehring et al. reported weak but significant correlations of endotoxin with allergens from mites and cats [21]. In our descriptive analysis, the prevalence of child participants aged 6 years or younger seemed to be higher in the cluster where endotoxin levels were greater. This is consistent with previous reports that the presence of young children is a predictor of endotoxin in homes $[8,12]$. Cluster 3 had the highest proportion people with a low socio-economic status which may be associated with increased levels of bio-contaminants in homes $[8,12,22,23]$. There is also ample evidence linking low socio-economic status with the high levels of cockroach, mouse, and rat allergens in homes [24, 25]. Cluster 2 had the highest prevalence of pet ownership and had endotoxin concentrations above the population average. Pets are known predictors of endotoxin in homes, as they tend to have Gram-negative bacteria in the gut and on the skin, from which they are shed $[8,22,26]$. Cluster 2 also had high levels of Alternaria alternata, which is consistent with a previous analysis of the National Survey of Lead and Allergens in Housing (NSLAH) that reported that cats and 
Table 4 Association between clusters with high endotoxin and asthma, wheeze, and sensitization to inhalant allergens in all participants, NHANES 2005-2006

\begin{tabular}{|c|c|c|c|c|c|c|c|c|c|}
\hline \multirow[t]{2}{*}{ Clusters } & \multicolumn{3}{|l|}{ Current asthma } & \multicolumn{3}{|c|}{ Wheeze in past 12 months } & \multicolumn{3}{|c|}{$\underline{\text { Sensitization to inhalant allergens }}$} \\
\hline & OR $(95 \% \mathrm{Cl})$ & P & $P_{\text {interaction }}$ & OR $(95 \% \mathrm{Cl})$ & $P$ & $P_{\text {interaction }}$ & OR $(95 \% \mathrm{Cl})$ & $P$ & $P_{\text {interaction }}$ \\
\hline \multicolumn{10}{|l|}{ Cluster 2 versus 1} \\
\hline In all participants & $1.42(1.06,1.91)$ & 0.02 & & $1.32(1.07,1.63)$ & 0.01 & & $1.10(0.89,1.34)$ & 0.37 & \\
\hline \multicolumn{10}{|l|}{ By age } \\
\hline In children & $1.06(0.62,1.81)$ & 0.83 & 0.25 & $0.98(0.70,1.36)$ & 0.90 & 0.002 & $0.70(0.42,1.17)$ & 0.17 & 0.009 \\
\hline In adults & $1.53(1.06,2.20)$ & 0.02 & & $1.43(1.15,1.78)$ & 0.001 & & $1.19(0.95,1.50)$ & 0.13 & \\
\hline \multicolumn{10}{|l|}{ By sensitization status } \\
\hline Sensitized & $1.15(0.83,1.57)$ & 0.40 & 0.21 & $1.52(1.09,2.13)$ & 0.01 & 0.49 & & & \\
\hline Non-sensitized & $1.82(0.97,3.43)$ & 0.06 & & $1.24(0.86,1.81)$ & 0.25 & & & & \\
\hline \multicolumn{10}{|l|}{ By exposure to ETS } \\
\hline Exposed to ETS & $1.50(0.79,2.84)$ & 0.21 & 1.00 & $1.54(0.94,2.50)$ & 0.085 & 0.35 & $0.99(0.54,1.82)$ & 0.98 & 0.48 \\
\hline Non-exposed to ETS & $1.41(0.99,2.00)$ & 0.06 & & $1.28(1.05,1.57)$ & 0.01 & & $1.12(0.95,1.31)$ & 0.16 & \\
\hline \multicolumn{10}{|l|}{ Cluster 3 versus 1} \\
\hline In all participants & $1.05(0.76,1.44)$ & 0.78 & & $1.01(0.82,1.24)$ & 0.92 & & $0.99(0.86,1.14)$ & 0.85 & \\
\hline \multicolumn{10}{|l|}{ By age } \\
\hline In children & $1.10(0.69,1.76)$ & 0.69 & 0.95 & $0.99(0.69,1.41)$ & 0.94 & 0.56 & $0.69(0.44,1.06)$ & 0.09 & 0.02 \\
\hline In adults & $0.98(0.66,1.46)$ & 0.93 & & $1.01(0.79,1.28)$ & 0.94 & & $1.07(0.94,1.22)$ & 0.32 & \\
\hline \multicolumn{10}{|l|}{ By sensitization status } \\
\hline Sensitized & $1.11(0.80,1.55)$ & 0.52 & 0.83 & $1.42(1.06,1.91)$ & 0.02 & 0.02 & & & \\
\hline Non-sensitized & $1.03(0.63,1.68)$ & 0.90 & & $0.81(0.61,1.07)$ & 0.14 & & & & \\
\hline \multicolumn{10}{|l|}{ By exposure to ETS } \\
\hline Exposed to ETS & $1.16(0.70,1.93)$ & 0.55 & 0.65 & $1.72(1.14,2.60)$ & 0.01 & 0.003 & $0.81(0.42,1.59)$ & 0.55 & 0.56 \\
\hline Non-exposed to ETS & $1.04(0.74,1.45)$ & 0.84 & & $0.84(0.64,1.09)$ & 0.18 & & $1.03(0.95,1.12)$ & 0.46 & \\
\hline
\end{tabular}

Abbreviations: OR odds ratio; $\mathrm{Cl}$ confidence interval; ETS environmental tobacco smoke. Odds ratios for the associations between the clusters and asthma and wheeze calculated using logistic regression. Models adjusted for age, gender, race/ethnicity, poverty income ratio, and ETS (except when the analysis was stratified by ETS)

dogs are predictors of this fungus in U.S. homes [27]. Participants in Cluster 3 were more likely to live in homes with mildew or musty smell or in a trailer. These participants had concentrations of endotoxin and allergens from fungus, cockroach, mite, and rodents higher than the study population average as well. In addition to being a predictor for endotoxin, indoor dampness is known to increase the risk of indoor fungal growth and exposure to mites and cockroach allergens [28, 29]. High exposure to endotoxin and mouse, cockroach allergens in trailer and mobile homes has also been reported in previous studies [30, 31].

We found the clustering of endotoxin with Alternaria and pet allergens (Cluster 2) was positively associated with current asthma and wheeze. In line with these results, we recently reported that exposure to cat and dog allergens enhances the relationship of endotoxin with asthma and wheeze [32]. This is consistent with previous reports that dog ownership might increase the association of pollutants with asthma [33]. However, there have been studies that found that both endotoxin as well as dog ownership might decrease asthma and allergy risk
$[16,34]$. It has been reported that these inverse associations were age-dependent and seem to occur in childhood during a narrow window of development [16]. This is consistent with our finding of the association of Cluster 2 with asthma outcomes only in adults $[35,36]$. Regarding the exposure and sensitization to pets in relation to asthma outcomes, Gergen et al. reported that exposure to dog and cat allergens was associated with excess asthma attacks in NHANES participants sensitized to pet allergens who had asthma [37]. Alternaria, the other component of Cluster 2 is known to be associated with asthma outcomes [27, 38]. The clustering of endotoxin with allergens from Aspergillus, cockroach, dust mites, and rodent allergens (Cluster 3) was associated with wheeze in the past 12 months in participants sensitized to inhalant allergens. In line with this finding, an analysis of the National Survey of Lead and Allergens in Housing (NSLAH) data also showed that the high allergen burden was associated with asthma only in atopic participants [15]. Endotoxin, as well as every allergen of the cluster was previously reported to be independently associated 
with both asthma and wheeze regardless of sensitization status [27, 39-41]. However, we do not know how the exposure to all these allergens interact to affect asthma. Clusters 2 and 3 were associated in participants who were sensitized mainly to house dust mites. We previously reported that individuals sensitized to inhalant allergens are particularly susceptible to respiratory outcomes related to endotoxin alone or with other coexposures [9, 19, 32]. Endotoxin seems to have worse respiratory effects in sensitized individuals by contributing to goblet cell hyperplasia and subsequent mucus hypersecretion that can aggravate inflammation $[8,9]$. The reason specific sensitization to dust mites was a modifier of the association of clusters with asthma outcomes is unclear. However, house dust mites have been shown to increase the allergenicity of endotoxin by facilitating its interactions with TLR4 [42]. Cluster 3 was also positively associated with wheeze in the past 12 months in participants exposed to ETS. Animal models have shown that exposure to cigarette smoke increases the expression and activity of Toll-like receptor (TLR)-4, and therefore increases its sensitivity to endotoxin [43]. Matsui et al. found similar results in humans. They reported a significantly higher risk of endotoxin-related asthma outcomes in children who had high exposure to cigarette smoke [44].

Our study has some limitations. First, it was crosssectional and the temporality between the exposures and the outcomes was unknown. Current asthma and wheeze in the past 12 months were defined by self-report and could not be confirmed. Endotoxin was sampled and measured once, but it has been suggested that endotoxin in bed and or bedroom floor stays stable for approximately a year [45]. Endotoxin was sampled in dust and it has been shown that dust endotoxin has only a modest correlation with airborne endotoxin [46]. Nevertheless, our study had major strengths. It is the first to examine the clustering patterns of endotoxin with other allergens in house dust. It includes a large sample representative of the U.S. population, which provided sufficient power to facilitate subgroup analysis on the significant effect modifiers. The endotoxin exposure assessment employed state-of-the-art techniques with extreme quality control measures. Our analysis also included a wide panel of allergens.

In conclusion, high endotoxin tends to cluster with other allergens in house dust. The clusters with high endotoxin levels are all associated with asthma or wheeze outcomes in specific subgroups of the population. We previously showed that household endotoxin decrease is effective in reducing the frequency of asthma symptoms [13]. Other studies have also examined the effectiveness of multiple trigger intervention strategies in improving asthma control $[47,48]$. Future studies should evaluate whether reducing the levels of endotoxin and allergens, specifically in the homes of people who own pets and of those with low socioeconomic status, might have a greater impact in preventing asthma symptoms and perhaps reduce future incidence of other respiratory diseases such as chronic obstructive pulmonary diseases.

\section{Supplementary information}

Supplementary information accompanies this paper at https://doi.org/10. 1186/s12940-020-00585-y.

\section{Additional file 1 : Table S1. Effect modification $P$-values by} sensitization to specific inhalant allergens on association between clusters and asthma outcomes, NHANES 2005-2006. Table S2. Association between clusters with high endotoxin and asthma outcomes by sensitization to dust mites, NHANES 2005-2006.

\section{Acknowledgements}

The authors acknowledge Dr. Nervana Metwali for leading the analysis of the NHANES dust samples for endotoxin.

\section{Authors' contributions}

Angelico Mendy assisted with development of the research questions and data analysis and was principal author of this manuscript. Peter S. Thorne directed the endotoxin analysis of the NHANES samples, contributed to the study design, collaborated on development of the research questions and edited the manuscript. Darryl C. Zeldin and Päivi Salo contributed to the conception, hypothesis delineation and design of this component of the NHANES study. Jesse Wilkerson contributed to the statistical analysis and interpretation of the data. All authors provided edits and comments on the manuscript.

\section{Funding}

Sample extraction and endotoxin analysis work at the University of lowa was funded by CDC/NCHS (200-2010-34238 NCE1). Data analysis was funded through a grant to the University of lowa, Environmental Health Sciences Research Center (NIH P30 ES005605), the University of lowa Center for Health Effects of Environmental Contamination (CHEEC), and through a contract to Social \& Scientific Systems (HHSN273201600002). This work was also funded, in part, by the Intramural Research Program of the $\mathrm{NIH}$, National Institute of Environmental Health Sciences (NIH Z01 ES025041).

\section{Availability of data and materials}

NHANES data are publicly available for data collection and analysis at https:// wwwn.cdc.gov/nchs/nhanes/Default.aspx. The analytic methods and SAS Codes will be made available to other researchers for purposes of reproducing the results or replicating the procedure on request.

\section{Ethics approval and consent to participate}

The Institutional Review Boards of the Centers for Disease Control and Prevention (CDC) and the National Center for Health Statistics (NCHS) approved the NHANES protocols and informed consent was obtained from all participants. Details of the IRB approval are available at http:// www.cdc.gov/nchs/nhanes/irba98.html.

\section{Consent for publication}

All authors approved the manuscript and this submission.

\section{Competing interests}

The authors have no actual or potential competing financial interests.

\section{Author details}

${ }^{1}$ Department of Occupational and Environmental Health, University of lowa, lowa City, lowa, USA. ${ }^{2}$ Social \& Scientific Systems, Durham, North Carolina, USA. ${ }^{3}$ Division of Intramural Research, National Institute of Environmental Health Sciences, NIH Research Triangle Park, Durham, North Carolina, USA. ${ }^{4}$ University of lowa College of Public Health, 100 CPHB, S341A, $145 \mathrm{~N}$ Riverside Dr, lowa City, IA 52242-2207, USA. 
Received: 8 October 2019 Accepted: 28 February 2020 Published online: 16 March 2020

\section{References}

1. Pepe C, Foley S, Shannon J, Lemiere C, Olivenstein R, Ernst P, et al. Differences in airway remodeling between subjects with severe and moderate asthma. J Allergy Clin Immunol. 2005;116(3):544-9.

2. Soriano JB, Abajobir AA, Abate KH, Abera SF, Agrawal A, Ahmed MB, et al. Global, regional, and national deaths, prevalence, disability-adjusted life years, and years lived with disability for chronic obstructive pulmonary disease and asthma, 1990-2015: a systematic analysis for the global burden of disease study 2015. Lancet Respir Med. 2017;5(9):691-706.

3. Centers for Disease Control and Prevention (CDC). Asthma. Data, Statistics, and Surveillance. Most Recent Asthma Data. https://www.cdc.gov/asthma/ most_recent_data.htm. Accessed 15 Feb 2018.

4. Nunes C, Pereira AM, Morais-Almeida M. Asthma costs and social impact. Asthma Res Pract. 2017;3(1):1

5. Fireman P. Symposium: Understanding Asthma Pathophysiology. Allergy Asthma Proc. 2003;24(2)

6. Etzel RA. How environmental exposures influence the development and exacerbation of asthma. Pediatrics. 2003;112(1 Pt 2):233-9.

7. Thorne PS, Kulhankova K, Yin M, Cohn R, Arbes SJ Jr, Zeldin DC. Endotoxin exposure is a risk factor for asthma: the national survey of endotoxin in United States housing. Am J Respir Crit Care Med. 2005;172(11):1371-7.

8. Thorne PS, Mendy A, Metwali N, Salo P, Co C, Jaramillo R, Rose KM, Zeldin DC. Endotoxin exposure: predictors and prevalence of associated asthma outcomes in the US. Am J Respir Crit Care Med. 2015;192(11):1287-97.

9. Mendy A, Salo PM, Cohn RD, Wilkerson J, Zeldin DC, Thorne PS. House Dust Endotoxin Association with Chronic Bronchitis and Emphysema. Environ Health Perspect. 2018;126(3).

10. Stein MM, Hrusch CL, Gozdz J, Igartua C, Pivniouk V, Murray SE, et al. Innate immunity and asthma risk in Amish and Hutterite farm children. N Engl J Med. 2016:375(5):411-21.

11. Mendy A, Cohn RD, Thorne PS. Endotoxin exposure, serum vitamin D, asthma and wheeze outcomes. Respir Med. 2016;114:61-6.

12. Thorne PS, Cohn RD, Mav D, Arbes SJ, Zeldin DC. Predictors of endotoxin levels in US housing. Environ Health Perspect. 2009;117(5):763.

13. Mendy A, Metwali N, Perry SS, Chrischilles EA, Wang K, Thorne PS. Household endotoxin reduction in the Louisa environmental intervention project (LEIP) for rural childhood asthma. Indoor Air. 2020;30(1):88-97.

14. Leaderer BP, Belanger K, Triche E, Holford T, Gold DR, Kim Y, et al. Dust mite, cockroach, cat, and dog allergen concentrations in homes of asthmatic children in the northeastern United States: impact of socioeconomic factors and population density. Environ Health Perspect. 2002;110(4):419-25.

15. Salo PM, Arbes Jr SJ, Crockett PW, Thorne PS, Cohn RD, Zeldin DC. Exposure to multiple indoor allergens in US homes and its relationship to asthma. J Allergy Clin Immunol 2008;121(3):678-684. e2.

16. Mendy A, Gasana J, Vieira ER, Forno E, Patel J, Kadam P, et al. Endotoxin exposure and childhood wheeze and asthma: a meta-analysis of observational studies. J Asthma. 2011:48(7):685-93.

17. Mendy A, Wilkerson J, Salo PM, Cohn RD, Zeldin DC, Thorne PS. Endotoxin predictors and associated respiratory outcomes differ with climate regions in the US. Environ Int. 2018;112:218-26.

18. Munir A, Björkstén B, Einarsson R, Schou C, Ekstrand-Tobin A, Warner A, et al. Cat (Fel d I), dog (can $\mathrm{fl}$ ), and cockroach allergens in homes of asthmatic children from three climatic zones in Sweden. Allergy. 1994:49(7):508-16.

19. Mendy A, Wilkerson J, Salo PM, Weir CH, Feinstein L, Zeldin DC, et al. Synergistic association of house endotoxin exposure and ambient air pollution with asthma outcomes. Am J Respir Crit Care Med. 2019;200(6):712-20.

20. Kozajda A, Bródka K, Sowiak M, Sobala W, Polańska K, Jurewicz J, et al. Children's residential exposure to selected allergens and microbial indicators: endotoxins and ( $1 \rightarrow 3$ )- $\beta$-D-glucans. Int J Occup Med Environ Health. 2013:26(6):870-89.

21. Gehring U, Heinrich J, Jacob B, Richter K, Fahlbusch B, Schlenvoigt G, et al, Respiratory symptoms in relation to indoor exposure to mite and cat allergens and endotoxins. Indoor factors and genetics in asthma (INGA) study group. Eur Respir J. 2001;18(3):555-63.

22. Bischof W, Koch A, Gehring U, Fahlbusch B, Wichmann H, Heinrich J. Predictors of high endotoxin concentrations in the settled dust of German homes. Indoor Air. 2002;12(1):2-9.
23. Chen C, Mielck A, Fahlbusch B, Bischof W, Herbarth O, Borte M, et al. Social factors, allergen, endotoxin, and dust mass in mattress. Indoor Air. 2007; 17(5):384-93.

24. Camacho-Rivera M, Kawachi I, Bennett GG, Subramanian S. Associations of neighborhood concentrated poverty, neighborhood racial/ethnic composition, and indoor allergen exposures: a cross-sectional analysis of Los Angeles households, 2006-2008. J Urban Health. 2014;91(4):661-76.

25. Sarpong SB, Hamilton RG, Eggleston PA, Adkinson NF. Socioeconomic status and race as risk factors for cockroach allergen exposure and sensitization in children with asthma. J Allergy Clin Immunol. 1996;97(6):1393-401.

26. Gehring U, Bischof W, Schlenvoigt G, Richter K, Fahlbusch B, Wichmann H, et al. Exposure to house dust endotoxin and allergic sensitization in adults. Allergy. 2004;59(9):946-52.

27. Salo PM, Yin M, Arbes SJ, Cohn RD, Sever M, Muilenberg M, et al. Dustborne Alternaria alternata antigens in US homes: results from the National Survey of Lead and allergens in housing. J Allergy Clin Immunol. 2005;116(3):623-9.

28. Bornehag C, Sundell J, Bonini S, Custovic A, Malmberg P, Skerfving S, et al Dampness in buildings as a risk factor for health effects, EUROEXPO: a multidisciplinary review of the literature (1998-2000) on dampness and mite exposure in buildings and health effects. Indoor Air. 2004;14(4):243-57.

29. Sharpe RA, Bearman N, Thornton CR, Husk K, Osborne NJ. Indoor fungal diversity and asthma: a meta-analysis and systematic review of risk factors. Allergy Clin Immunol. 2015;135(1):110-22.

30. Cohn RD, Arbes SJ, Yin M, Jaramillo R, Zeldin DC. National prevalence and exposure risk for mouse allergen in US households. J Allergy Clin Immunol. 2004:113(6):1167-71.

31. Platts-Mills TA, Vervloet D, Thomas WR, Aalberse RC, Chapman MD. Indoor allergens and asthma: report of the third international workshop. J Allergy Clin Immunol. 1997;100(6 Pt 1):S2-24.

32. Mendy A., Wilkerson J., Salo P.M., Cohn R.D., Zeldin D.C., Thorne P.S. Exposure and sensitization to pets modify endotoxin association with asthma and wheeze. J Allergy Clin Immunol Pract 2018;6(6):2006-2013.e4.

33. McConnell R, Berhane K, Molitor J, Gilliland F, Künzli N, Thorne PS, et al. Dog ownership enhances symptomatic responses to air pollution in children with asthma. Environ Health Perspect. 2006:1910-5.

34. Campo P, Kalra HK, Levin L, Reponen T, Olds R, Lummus ZL, et al. Influence of dog ownership and high endotoxin on wheezing and atopy during infancy. J Allergy Clin Immunol. 2006;118(6):1271-8.

35. Nafstad $P$, Magnus $P$, Gaarder $P$, Jaakkola J. Exposure to pets and atopyrelated diseases in the first 4 years of life. Allergy. 2001;56(4):307-12.

36. Svanes C, Heinrich J, Jarvis D, Chinn S, Omenaas E, Gulsvik A, et al. Pet-keeping in childhood and adult asthma and hay fever: European Community respiratory health survey. J Allergy Clin Immunol. 2003;112(2):289-300.

37. Gergen PJ, Mitchell HE, Calatroni A, Sever ML, Cohn RD, Salo PM, et al Sensitization and Exposure to Pets: The Effect on Asthma Morbidity in the US Population. J Allergy Clin Immunol Pract 2018;6(1):101-107.e2.

38. Pulimood TB, Corden JM, Bryden C, Sharples L, Nasser SM. Epidemic asthma and the role of the fungal mold Alternaria alternata. J Allergy Clin Immunol. 2007:120(3):610-7.

39. Phipatanakul W. Rodent allergens. Curr Allergy Asthma Rep. 2002;2(5):412-6

40. Calderón MA, Linneberg A, Kleine-Tebbe J, De Blay F, de Rojas DHF, Virchow JC, et al. Respiratory allergy caused by house dust mites: what do we really know? J Allergy Clin Immunol. 2015;136(1):38-48.

41. Rosenstreich DL, Eggleston P, Kattan M, Baker D, Slavin RG, Gergen P, et al. The role of cockroach allergy and exposure to cockroach allergen in causing morbidity among inner-city children with asthma. N Engl J Med. 1997;336(19):1356-63.

42. Trompette A, Divanovic S, Visintin A, Blanchard C, Hegde RS, Madan R, et al. Allergenicity resulting from functional mimicry of a toll-like receptor complex protein. Nature. 2009;457(7229):585-8.

43. Pace $\mathrm{E}$, Ferraro $\mathrm{M}$, Siena $\mathrm{L}$, Melis M, Montalbano AM, Johnson M, et al. Cigarette smoke increases toll-like receptor 4 and modifies lipopolysaccharidemediated responses in airway epithelial cells. Immunology. 2008;124(3):401-11.

44. Matsui EC, Hansel NN, Aloe C, Schiltz AM, Peng RD, Rabinovitch N, et al. Indoor pollutant exposures modify the effect of airborne endotoxin on asthma in urban children. Am J Respir Crit Care Med. 2013;188(10):1210-5.

45. Park JH, Spiegelman DL, Burge HA, Gold DR, Chew GL, Milton DK Longitudinal study of dust and airborne endotoxin in the home. Environ Health Perspect. 2000:108(11):1023-8.

46. Kilburg-Basnyat B, Peters TM, Perry SS, Thorne PS. Electrostatic dust collectors compared to inhalable samplers for measuring endotoxin concentrations in farm homes. Indoor Air. 2016;26(5):724-33. 
47. Krieger J, Jacobs DE, Ashley PJ, Baeder A, Chew GL, Dearborn D, et al. Housing interventions and control of asthma-related indoor biologic agents: a review of the evidence. J Public Health Manag Pract. 2010;16(5 Suppl):S11-20.

48. Takaro TK, Krieger J, Song L, Sharify D, Beaudet N. The breathe-easy home: the impact of asthma-friendly home construction on clinical outcomes and trigger exposure. Am J Public Health. 2011;101(1):55-62.

\section{Publisher's Note}

Springer Nature remains neutral with regard to jurisdictional claims in published maps and institutional affiliations.

Ready to submit your research? Choose BMC and benefit from:

- fast, convenient online submission

- thorough peer review by experienced researchers in your field

- rapid publication on acceptance

- support for research data, including large and complex data types

- gold Open Access which fosters wider collaboration and increased citations

- maximum visibility for your research: over $100 \mathrm{M}$ website views per year

At $\mathrm{BMC}$, research is always in progress.

Learn more biomedcentral.com/submissions 